\title{
Risk Assessment of Water Inrush in Karst Tunnels Based on the Efficacy Coefficient Method
}

\author{
Yingchao Wang ${ }^{1,2 *}$, Xin Yin ${ }^{1,2}$, Fan Geng ${ }^{3}$, Hongwen Jing ${ }^{1,2}$, \\ Haijian Su${ }^{1}$, Richeng Liu ${ }^{1}$ \\ ${ }^{1}$ State Key Laboratory for Geomechanics and Deep Underground Engineering, China University of Mining \\ and Technology, Xuzhou, Jiangsu 221116, China \\ ${ }^{2}$ School of Mechanics and Civil Engineering, China University of Mining and Technology, \\ Xuzhou, Jiangsu 221116, China \\ ${ }^{3}$ School of Electrical and Power Engineering, China University of Mining \& Technology, \\ Xuzhou, Jiangsu 221116, China
}

Received: 10 August 2016

Accepted: 15 October 2016

\begin{abstract}
Water inrush is one of the typical geological hazards of tunnel construction in karst areas. It is necessary to predict water inrush more accurately for karst tunnels. Firstly, we created a model on risk evaluation of water inrush based on the efficacy coefficient method. Then karst hydrologic and engineering geological conditions were considered in detail, and several typical factors were selected as evaluation indexes, including formation lithology, unfavorable geology, groundwater level, and so on. Moreover, the weight coefficients of the selected evaluation indices were calculated using the analytic hierarchy process method. Furthermore, the total efficacy coefficient was presented to specify the risk grade of the evaluation samples. Finally, the risk grade of water inrush for karst tunnels is divided into four levels: severe (red), high (orange), elevated (yellow), and guarded (blue). Additionally, the model of risk assessment of water inrush was applied to Jigongling tunnel along the Fanba Expressway in China. The results show that the present evaluation results agree well with the construction situation, which also agree with the relative analysis results of attribute mathematical theory. The presented work with the efficacy coefficient method is relatively simple with strong operability, which has potential for predicting water inrush in karst tunnels.
\end{abstract}

Keywords: water inrush, efficacy coefficient method, risk assessment, karst tunnels

\section{Introduction}

With the rapid development of China's economy, more and more long-deep tunnels are under construction,

*e-mail: wych12345678@126.com especially in the mountainous area of western China and in karst areas [1-2], which pose a great challenge for tunnel engineering. Long-deep tunnels are always buried in complex geological conditions with high geo-stress, high water pressure, strong karst geology, and construction disturbance [3]. Additionally, it is quite difficult to make a 
thorough investigation on engineering geology and hydrogeological conditions. Thus a lot of geological disasters have occurred during tunnel construction, such as water inrush, mud outburst, rock burst, and collapse, as well as gas outburst.

Among tunnel accidents, water inrush is regarded as one of the most serious problems throughout the world, which can directly lead to severe death and heavy economic loss. It has been reported that several water inrush accidents have occurred in karst tunnels in China from 2002 to 2011, causing 47 deaths [4]. Thus it is necessary to predict water inrush in tunnels. However, prediction theory and forecast method on tunnel water inrush in karst areas have long been a difficult hydro-geological problem [5]. The bottleneck problem on water rush has constrained the development of underground construction, particularly for long-deep tunnels. Therefore, it is of great significance to do research on predicting the occurrence probability of water inrush, and some effective countermeasures are needed to assure environmental safety and successful tunneling.

More and more research has been devoted to forecast tunnel water inrush, although such a thing is very difficult to predict accurately during tunnel construction [6]. Recent research related to the forecast method of tunnel water inrush can be divided into two main groups. On the one hand, finite element and finite difference schemes have been used to simulate tunnel water inrush under various complicated geological conditions [7]. However, most finite element models follow the traditional theory of elastic-plastic mechanics, which has been proven to be limited. Since the finite element models cannot adequately replicate the fracture initiation, propagation, and coalescence associated with the formation of a water inrush pathway in rock strata [8]. There are also some other models that have been established to investigate the fracture zone and the seepage rule using the software of RFPA2D and COMSOL [9]. On the other hand, a large number of researchers have proposed various methods derived from other fields to evaluate the risk of water inrush in tunnels. Wang et al. [10] evaluated the risk of floor water inrush in coal mines based on secondary fuzzy comprehensive evaluation. An attribute synthetic evaluation system was proposed for the risk evaluation of the water inrush in karst tunnels, which was performed with attribute mathematical theory. Chen et al. [11] employed FAT to analyze the hazard common source of mine water inrush. Probabilistic models for tunnel construction risk assessment were established based on the data gained from former tunnel projects, which could be used to estimate the time of tunnel construction and guide construction performance [12-13]. The fuzzy TOPSIS method was extensively used to solve multi-criteria decision-making problems for tunneling projects. Meanwhile, a new risk evaluation model was presented with consideration of the uncertainties and the new factors [14].

Additionally, risk evaluation has also been investigated for water inrush. Hodlur et al. [15] developed a statistical hydrogeological model to evaluate mine water hazards.
Bukowski [16] proposed an assessment system to classify mine shafts with respect to water hazard risk. Li et al. [17] integrated the artificial neural network (ANN), wavelet, analysis and fuzzy mathematics - namely the fuzzy wavelet neural network (FWNN) - which was then used to establish a model for risk assessment on karst tunnels. Based on water inrush coefficient (Ts) and unit-inflow (q), the safe-mining evaluation model was established to provide a convenient evaluation method for secure production [18]. Considering the lithology and the structure features, a coal floor water inrush risk assessment method was put forward according to a conventional water inrush coefficient [19]. Li et al. [20] studied the risk assessment system for water inrush in the karst tunnels with geographic information system (GIS) technology, which was used to dynamically predict the water inrush risk and develop appropriate protective measures. What's more, Bayesian probabilistic networks were applied to assess the risk in road tunnels, which was embodied in two aspects: firstly, a set of key performance indicators (KPI) were used to associate with risks. Secondly, relative data, models published in literature, and expert opinion were selected to sustain the dependencies and the conditional probabilities [21]. Wang et al. [22-27] proposed many new models to evaluate the risk of engineering geological hazards, such as water inrush, collapse, etc.

According to the above introduction, some methods are accompanied by simplified conditions or factors, which sometimes fail to reveal the quantified relationship between water inrush and its influence indices. However, other methods have certain limitations, though they could manage some problems of water inrush with their uniqueness. For one thing, the above methods are limited for evaluating the risk of water inrush in karst tunnels, which sometimes fail to reveal the quantifying relationship between water inrush and its influence factors. Because the influence factors of water inrush in karst tunnels are different from those of coal mines, the methods for coal mines may not be available for risk analysis of the water inrush in karst tunnels [6]. For another thing, the calculation processes of the above methods are too complicated to be used for a tunnel engineering site. Therefore, it is necessary to propose a simple and reliable method for risk evaluation of the water inrush in karst tunnels [6].

In the present work, a new analysis model was established using both the efficacy coefficient and analytic hierarchy process methods. Firstly, the efficacy coefficient method was put forward for single efficacy coefficient, which was performed with consideration of the main influence factors of water inrush. Then the considered factors were selected as evaluation indices. Moreover, the analytic hierarchy process method was presented to determine the weight coefficient for each evaluation index. Furthermore, based on the combination of the single efficacy coefficient and the weight coefficient, total efficacy coefficient was brought out to specify the risk grade of the evaluation samples. Additionally, the evaluation results were compared with the fieldobserved results and relative research results to validate 
the feasibility and effectiveness of the established analysis model, which could provide guidance to control the water inrush risk in karst tunnels.

\section{Analysis Model}

\section{Efficacy Coefficient Method}

The efficacy coefficient method is a quantitative evaluation method. It can not only reflect the complex characteristics of multiple factors, but also realize comprehensive analysis. Thus the efficacy coefficient method has been extensively employed by many researchers, including for risk assessment, which has been applied for geotechnical engineering and gained better results [28-29].

The efficacy coefficient method is proposed with the theory of multi-objective programming. On the first step, it is necessary to determine the influence factors for the investigated objects, and the main influence factors should be selected, which could better describe the objects. The main influence factors are regarded as evaluation indices to determine the evaluation index system of the objects. Then the single efficacy coefficients of the considered factors are presented for each evaluation index, which are then used to describe the factors' contributions to the objective system. However, the single efficacy coefficients are limited within certain ranges, including the satisfaction value and the non-permissible value. In addition, total efficacy coefficient is brought out based on the single efficacy coefficients of the selected factors. The evaluation process is listed in detail as follows:

\section{Determining the Evaluation Index System}

The evaluation system might have many influence factors, such as changes induced by the system, phases and aims of the system, and contrived factors. The influence factors should be considered in detail for the investigated object, and typical variables are selected from the multiple factors. The selected variables cannot only represent the characteristics of the investigated object as far as possible, but also must be feasible for the present method. Thus each selected variable is regarded as an evaluation index, and multiple evaluation indices make up the so-called evaluation index system for the investigated system. Additionally, the selection for evaluation index should follow certain principles, namely the selected factors should be representative for evaluation indices, which also should complement mutually without repetition.

\section{The Satisfaction and the Non-Permissible Values}

For each evaluation index, the single efficacy coefficient is introduced to describe the relative factors' contributions to the objective system. The single efficacy coefficients own their limited scope, ranging from the nonpermissible value to the satisfaction value. Namely, the satisfaction value is simply the highest value of the limited range, and the non-permissible value is the lowest value of the limited range. In general, the greater the efficacy coefficient, the better the comprehensive performance of the investigated object.

\section{Calculation of Single Efficacy Coefficients for each Evaluation Index}

For the evaluation index system, the single efficacy coefficients could be divided into four kinds separately for four types of variables of influence factors as follows:

- The first kind of single efficacy coefficient is related to the maximum variable. For this type of variable, the better the relative evaluation index, the bigger the single efficacy coefficient.

- The second kind of single efficacy coefficient is relative to the minimum variable. For this type of variable, the better the relative evaluation index, the smaller the single efficacy coefficient.

- The third kind of single efficacy coefficient is stable. The single efficacy coefficient of the third kind is highest at a certain point.

- The fourth kind of single efficacy coefficient is interval, and the single efficacy coefficient changes within a certain range.

Moreover, the detailed calculations for the above kinds of single efficacy coefficient above can be seen as follows.

1) The first kind of single efficacy coefficient

$$
d_{1 i}=\left\{\begin{array}{cc}
\frac{x_{i}-x_{s i}}{x_{h i}-x_{s i}} \times 40+60, & x_{i}<x_{h i} \\
100 & , x_{i} \geq x_{h i}
\end{array}\right.
$$

...where $i$ represents the $i$ th evaluation index, $x_{\mathrm{i}}$ is the actual value of the $i$ th evaluation index, $x_{\mathrm{hi}}$ is the satisfaction value of the $i$ th evaluation index, and $x_{\mathrm{si}}$ is the non-permissible value of the $i$ th evaluation index. In addition, $d_{1 \mathrm{i}}$ is the single efficacy coefficient for the $i$ th evaluation index of the maximum variable.

2) The second kind of single efficacy coefficient

$$
d_{2 i}=\left\{\begin{array}{cc}
\frac{x_{i}-x_{s i}}{x_{h i}-x_{s i}} \times 40+60, & x_{i}>x_{s i} \\
100 \quad, & x_{i} \leq x_{s i}
\end{array}\right.
$$

...where $d_{2 \mathrm{i}}$ is the single efficacy coefficient for the $i$ th evaluation index of the minimum variable.

3) The third kind of single efficacy coefficient 


$$
\left.d_{3 i}=\left(1-\left|x_{i}-x_{h i}\right|\right) /\left|x_{s i}-x_{h i}\right|\right) \times 40+60
$$

...where $d_{3 \mathrm{i}}$ is the single efficacy coefficient for the $i$ th evaluation index of stable variable.

4) The fourth kind of single efficacy coefficient

$$
d_{4 i}= \begin{cases}{\left[1-\frac{\left(x_{\min }-x_{i}\right)}{x_{\text {min }}-x_{s \min }}\right] \times 40+60,} & x_{i}<x_{\min } \\ 100 & , x_{\min } \leq x \leq x_{\max } \\ {\left[1-\frac{\left(x_{\min }-x_{i}\right)}{x_{h \max }-x_{\max }}\right] \times 40+60,} & x_{i}>x_{\max }\end{cases}
$$

...where $x_{\min }$ represents the lower limit value of the interval variable and $x_{\max }$ represents the upper limit value of the interval variable. $x_{\sin }$ represents the non-permissible value of the lower limit value, and is generally equal to half value of the average value for all interval variables. What's more, $x_{\text {hmax }}$ is the non-permissible value of the upper limit value, and is generally equal to one of the average values for all interval variables. In addition, $d_{4 \mathrm{i}}$ is the single efficacy coefficient for the $i$ th evaluation index of interval variable.

\section{Total Efficacy Coefficient}

Based on the above four kinds of single efficacy coefficients, the total efficacy coefficient, $D$, can be described as:

$$
D=\sum_{i=1}^{m} d_{i} \omega_{i}
$$

...where $d_{i}$ is the single efficacy coefficient of the $i$ th evaluation index and $\omega_{i}$ is the normalized weight coefficient of the $i$ th evaluation index. The weight coefficient can be determined using the analytic hierarchy process method, which can be seen as follows.

\section{Principle of the Analytic Hierarchy Process Method}

The analytic hierarchy process (AHP) was put forward by Thomas Saaty in 1980. AHP mainly performs with the help of mathematics and psychology. In detail, a complicated decision is investigated and reduced to a series of pairwise comparisons that are analyzed and synthesized. Then the AHP is applied to capture both the subjective aspects and the objective aspects of the decision. Additionally, the AHP provides a useful way to check the consistency of evaluations from the decision maker, which can reduce prejudice when making the decision. Moreover, the AHP has been validated as an effective way to analyze the complicated decisions that have been employed in many fields, including environmental assessment, program and policy evaluation, activity analysis, and performance evaluation.

When using the AHP, the procedure can be summarized as follows [30]:

1. An investigated object is selected, and the objective problem was modeled as a hierarchy that contains the decision goal, the alternatives, and the criteria to evaluate the alternatives.

2. Priorities among the elements of the hierarchy are established through a series of judgments that performs with the pairwise comparisons of the elements.

3. The obtained judgments are synthesized to yield a set of overall priorities for the hierarchy.

4. The consistency of the judgments is checked.

5. A final decision can be gained according to the above processes.

\section{Establishing a Hierarchy for the Objective Problem}

According to the above processes, it is necessary to treat the objective problem as a hierarchy at the first step. After analyzing the objectives and the relative problems, multiple influence factors are selected as the evaluation indices, which can be divided into several levels that range from the highest level to the lowest level. In addition, each element in each level is independent from the other.

\section{Structure Judgment Matrices}

Once the hierarchy is constructed, its various elements are evaluated by comparing them to each other two at a time, with respect to their impact on an element above them in the hierarchy. The relative importance between two criteria is assigned values using 1 to 9, as shown in Table 1. The structure of judgment matrices can be therefore constructed, as shown in Table 2.

\section{Calculating Weight Vectors}

For each pairwise in the comparison matrix, the maximum eigenvalues and the corresponding eigenvectors are calculated using the summation method as described below:

(1) Each column vector of the judgment matrix, $\omega_{i j}^{\prime}$, is calculated using Eq. 6:

$$
\omega_{i j}^{\prime}=b_{i j} / \sum_{i=1}^{n} b_{i j}
$$

... where $\omega_{i j}^{\prime}$ is the column vector of the judgment matrix, $b_{\mathrm{ij}}$ is an element of the judgment matrix $(B)$, and each element $\left(b_{\mathrm{ij}}\right)$ represents the importance of the $i$ th criterion relative to the $j$ th criterion. If $b_{\mathrm{ij}}>1$, then the $i$ th criterion is more important than the $j$ th criterion, while if $b_{\mathrm{ij}}<1$, then 
Table 1. The meaning of the 1-9 grade standard.

\begin{tabular}{|c|c|}
\hline Value of $b_{\mathrm{ij}}$ & Interpretation \\
\hline 1 & $i$ and $j$ are equally important \\
\hline 3 & $i$ is slightly more important than $j$ \\
\hline 5 & $i$ is more important than $j$ \\
\hline 7 & $i$ is strongly more important than $j$ \\
\hline 9 & $i$ is absolutely more important than $j$ \\
\hline $2,4,6,8$ & the middle of two adjacent judgments \\
\hline Reciprocal & $\begin{array}{r}\text { When } i \text { and } j \text { are compared, the scalar is the } \\
\text { reciprocal of } i \text { and } j \text { calar. }\end{array}$ \\
\hline
\end{tabular}

Table 2. The structure of the judgment matrix.

\begin{tabular}{|c|c|c|c|c|}
\hline $\mathrm{B}$ & $b_{1}$ & $b_{2}$ & --- & $b_{n}$ \\
\hline$b_{1}$ & $b_{11}$ & $b_{12}$ & -- & $b_{1 n}$ \\
\hline$b_{2}$ & $b_{21}$ & $b_{22}$ & --- & $b_{2 n}$ \\
\hline$\vdots$ & $\vdots$ & $\vdots$ & $\vdots$ & $\vdots$ \\
\hline$b_{n}$ & $b_{n 1}$ & $b_{n 2}$ & --- & $b_{n n}$ \\
\hline
\end{tabular}

the $i$ th criterion is less important than the $j$ th criterion. If two criteria have the same importance, then the entry $b_{\mathrm{ij}}$ is 1 . The value of $b_{\mathrm{ij}}$ is measured according to a numerical scale from 1 to 9 , as shown in Table 1.

(2) The sum of values in the $j$ th row of the judgment matrix, $\omega_{i}^{\prime}$, is calculated by Eq. 7:

$$
\omega_{i}^{\prime}=\sum_{j=1}^{n} \omega_{j}^{\prime}
$$

... where $\omega_{i}^{\prime}$ represents the values in $j$ th row of the judgment matrix.

(3) The feature vector, $\omega_{i}$, is obtained by Eq. 8 :

$$
\omega_{i}=\omega_{i}^{\prime} / \sum_{i=1}^{n} \omega_{i}^{\prime}
$$

(4) The maximum eigenvalue, $\lambda_{\max }$, is calculated by Eq. 9:

$$
\lambda_{\max }=\frac{1}{n} \sum_{i=1}^{n} \frac{(B \omega)_{i}}{\omega_{i}}
$$

\section{Consistency Test of Judgment Matrix}

The judgment matrix is generally established based on the subjective judgment of the actual situation and this may cause some inaccuracies in the numerical matrix. Therefore, a criterion is necessary to test the consistency of the judgment matrix. For the consistency test, the formula can be described as follows:

$$
C R=C I / R I
$$

...where $C R$ is the consistency ratio; when $C R<0.1$, the judgment matrix is acceptable, otherwise the judgment matrix should be revised. $R I$ is the average random consistency index, which can be determined according to Table 3. CI is the consistency index of the definition:

$$
C I=\left(\lambda_{\max }-n\right) /(n-1)
$$

$\ldots$ where $\lambda_{\max }$ is the maximum eigenvalue and $n$ is the number of factors in pairs.

\section{Process for Model Calculation and Model Test}

\section{Analysis of Evaluation Indices and System}

Water inrush in karst tunnels is a complicated geological hazard. There are a large number of influence factors of water inrush in karst tunnels, thus it is important to select the evaluation indices from all influence factors of water inrush. Influence factors of water inrush can be divided into two groups, namely concerning geological factors and engineering factors. In the present work, only the geological factors are considered because engineering factors are non-essential for risk assessment during the design stage and the static evaluation of water inrush [6].

With the consideration of the correlation of influence factors, the values of influence factors were easily tested and obtained. According to relative research findings $[6,30]$, seven major factors were selected as evaluation indices in the present work, including formation lithology, groundwater level, landform and physiognomy, unfavorable geological conditions, modified strata inclination, contact zones of dissolvable and insoluble rock, and layer and interlayer fissures. Meanwhile, unfavorable geological conditions were associated with three influence factors, including water-bearing structure, the catchments area of the karst water system, and the width of the fault fracture zone. Then a hierarchy model of the influence factors for water inrush in karst tunnels was established, as shown in Fig. 1.

According to the relative research of $\mathrm{Li}$, et al. (2013), the standards of the risk grade for water inrush have been studied, and the relative information is shown in Table 4. The evaluation indices are divided into four separate grades as Levels I-IV. For the four grades, the

Table 3. The value of random consistency index $R I$.

\begin{tabular}{|c|c|c|c|c|c|c|c|c|c|}
\hline $\begin{array}{c}\text { Order of } \\
\text { judgment } \\
\text { matrix }\end{array}$ & 1 & 2 & 3 & 4 & 5 & 6 & 7 & 8 & 9 \\
\hline RI & 0 & 0 & 0.58 & 0.90 & 1.12 & 1.24 & 1.32 & 1.41 & 1.45 \\
\hline
\end{tabular}




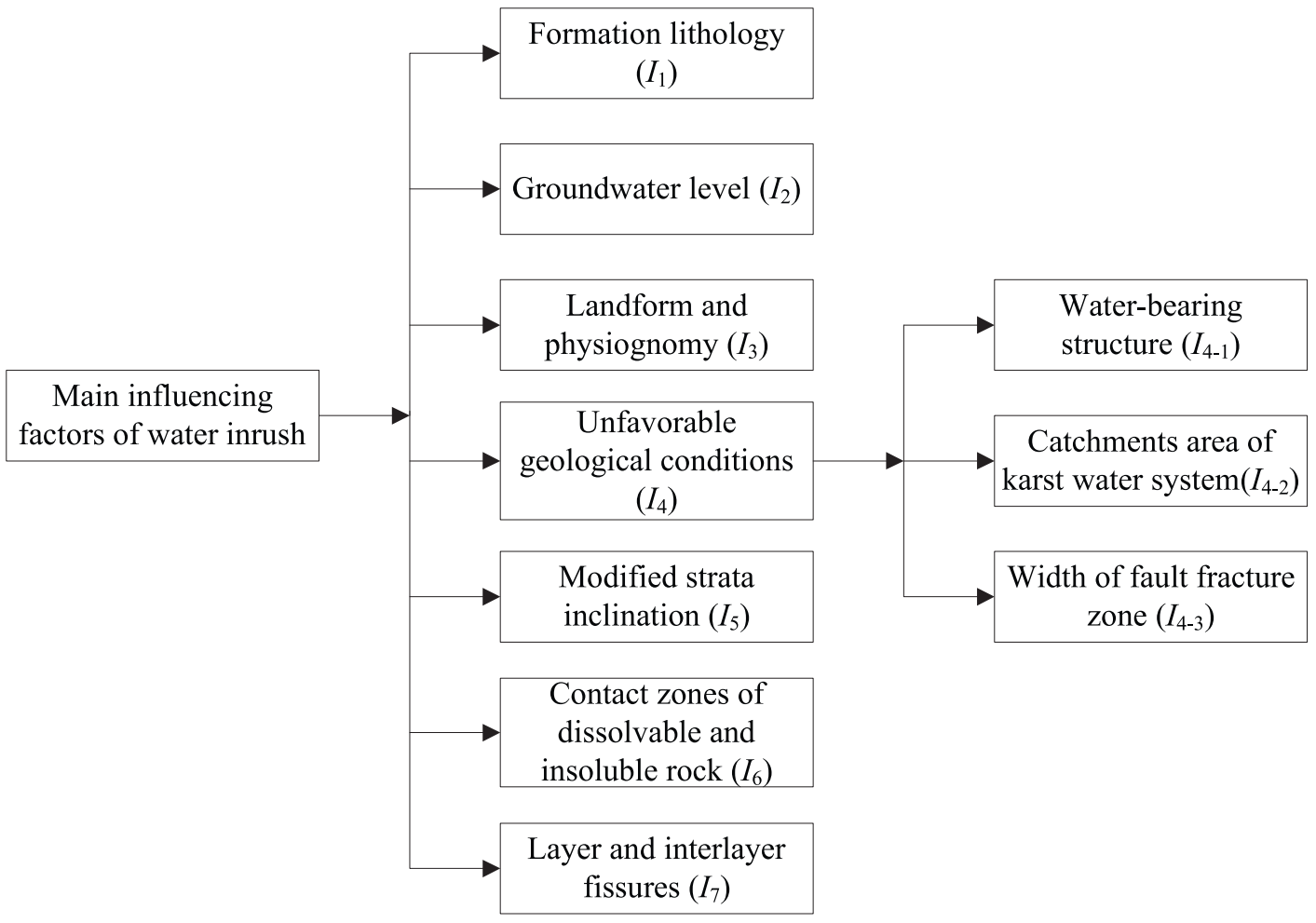

Fig. 1. Hierarchy model of the influence factors for water inrush in karst tunnels.

occurrence probability of water inrush decreases in turn. In the present work, the grade standards of water inrush were also applied for the risk assessment of water inrush. However, the grade standard was established based on the expert evaluation method, since it is difficult to quantitatively evaluate some indices such as unfavorable geological conditions, contact zones of dissolvable and insoluble rock, and layer and interlayer fissures. Meanwhile, formation lithology was used for the quantitative classification through expert evaluation method, or by a parameter of rock solubility $(t)$ [30].

\section{Determining the Satisfaction and Non-Permissible Values}

The satisfaction value and the non-permissible value are important for risk assessment. According to previous research results, the satisfaction value and the nonpermissible value could be determined by considering the risk grade standards and the evaluation indices of water inrush. In the present work, the two values should also be determined, which was not only according to the calculation principle but also based on the actual level that can be achieved. Moreover, the satisfaction value was regarded as the highest level for an index of the evaluation standard, while the non-permissible value was thought to be the lowest level for the index of the evaluation standard. According to risk grade standards of water inrush, the satisfaction value for an index is the highest value of the limited range for I (severe), while the non-permissible value for the referred index corresponds to the lowest value of the limited range for IV (guarded), as shown in Table 4. Additionally, the satisfaction value and the non-permissible value for each index are presented in Table 5 .

Table 4. Evaluation indices and risk grade standards of water inrush.

\begin{tabular}{|c|c|c|c|c|c|c|c|c|}
\hline \multirow{2}{*}{$\begin{array}{l}\text { Evaluation } \\
\text { index }\end{array}$} & \multicolumn{2}{|c|}{ Formation lithology } & \multirow{2}{*}{$\begin{array}{c}\text { Groundwater } \\
\text { level, } \mathrm{m}\end{array}$} & \multirow{2}{*}{$\begin{array}{c}\begin{array}{c}\text { Landform and } \\
\text { physiognomy } \\
\text { (proportion of } \\
\text { negative landform } \\
\text { area), \% }\end{array}\end{array}$} & \multirow{2}{*}{$\begin{array}{l}\text { Unfavorable } \\
\text { geological } \\
\text { conditions }\end{array}$} & \multirow{2}{*}{$\begin{array}{c}\text { Modified } \\
\text { strata } \\
\text { inclination, } \\
\mathbf{o}\end{array}$} & \multirow{2}{*}{$\begin{array}{c}\text { Contact } \\
\text { zones of } \\
\text { dissolvable } \\
\text { and insoluble } \\
\text { rock }\end{array}$} & \multirow{2}{*}{$\begin{array}{c}\text { Layer and } \\
\text { interlayer } \\
\text { fissures }\end{array}$} \\
\hline & $\begin{array}{c}\text { Rock } \\
\text { solubility, } t\end{array}$ & $\begin{array}{c}\text { Expert } \\
\text { evaluation }\end{array}$ & & & & & & \\
\hline I (Severe) & $>0.254$ & $0 \sim 60$ & $>60$ & $>60$ & $0 \sim 60$ & $25 \sim 45$ & $0 \sim 60$ & $0 \sim 60$ \\
\hline II (High) & $0.104 \sim 0.254$ & $60 \sim 70$ & $30 \sim 60$ & $40 \sim 60$ & $60 \sim 70$ & $10 \sim 25$ & $60 \sim 70$ & $60 \sim 70$ \\
\hline III (Elevated) & $0.042 \sim 0.104$ & $70 \sim 85$ & $10 \sim 30$ & $20 \sim 40$ & $70 \sim 85$ & $5 \sim 10$ & $70 \sim 85$ & $70 \sim 85$ \\
\hline IV (Guarded) & $0 \sim 0.042$ & $85 \sim 100$ & $<10$ & $0 \sim 20$ & $85 \sim 100$ & $0 \sim 5$ & $85 \sim 100$ & $85 \sim 100$ \\
\hline
\end{tabular}


Table 5. Satisfaction and non-permissible values for each index.

\begin{tabular}{|c|c|c|c|c|c|c|c|}
\hline Index & $\begin{array}{c}\text { Formation } \\
\text { lithology } t\end{array}$ & $\begin{array}{c}\text { Groundwater } \\
\text { level, } \mathrm{m}\end{array}$ & $\begin{array}{c}\text { Landform and } \\
\text { physiognomy, } \\
\%\end{array}$ & $\begin{array}{c}\text { Unfavorable } \\
\text { geological } \\
\text { conditions }\end{array}$ & $\begin{array}{c}\text { Modified } \\
\text { strata } \\
\text { inclination, }\end{array}$ & $\begin{array}{c}\text { Contact zones } \\
\text { of dissolvable } \\
\text { and insoluble } \\
\text { rock }\end{array}$ & $\begin{array}{c}\text { Layer and } \\
\text { interlayer } \\
\text { fissures }\end{array}$ \\
\hline $\begin{array}{c}\text { Satisfaction } \\
\text { value }\end{array}$ & 0.254 & 60 & 60 & 100 & 45 & 100 & 100 \\
\hline $\begin{array}{c}\text { Non- } \\
\text { permissible } \\
\text { value }\end{array}$ & 0 & 0 & 0 & 0 & 0 & 0 & 0 \\
\hline
\end{tabular}

\section{Calculation of Single Efficacy Coefficients}

Formation lithology, groundwater level, landform and physiognomy (proportion of negative landform area), and modified strata inclination were regarded as maximum variables that could be calculated using Eq. (1). Meanwhile, the other variables could be calculated using Eq. (2), such as unfavorable geological conditions, and contact zones of dissolvable and insoluble rock, layer, and interlayer fissures.

Table 6. Analysis of risk grade of water inrush.

\begin{tabular}{|c|c|c|c|}
\hline $\begin{array}{c}\text { Risk } \\
\text { grade }\end{array}$ & $\begin{array}{c}\text { Total efficacy } \\
\text { coefficient }\end{array}$ & $\begin{array}{c}\text { Warning } \\
\text { signal }\end{array}$ & $\begin{array}{c}\text { Supplemental } \\
\text { instruction }\end{array}$ \\
\hline I & $\geq 90$ & Red & $\begin{array}{c}\text { Risk of water inrush } \\
\text { is severe }\end{array}$ \\
\hline II & $80 \sim 90$ & Orange & $\begin{array}{c}\text { Risk of water inrush } \\
\text { is high }\end{array}$ \\
\hline III & $70 \sim 80$ & Yellow & $\begin{array}{c}\text { Risk of water inrush } \\
\text { is elevated }\end{array}$ \\
\hline IV & $60 \sim 70$ & Blue & $\begin{array}{c}\text { Risk of water inrush } \\
\text { is guarded }\end{array}$ \\
\hline
\end{tabular}

Table 7. Judgment matrix for weights analysis of each index $I_{i}$.

\begin{tabular}{|c|c|c|c|c|c|c|c|c|}
\hline $\begin{array}{c}\text { Evaluation } \\
\text { indices }\end{array}$ & $I_{1}$ & $I_{2}$ & $I_{3}$ & $I_{4}$ & $I_{5}$ & $I_{6}$ & $I_{7}$ & $\omega_{i}$ \\
\hline$I_{1}$ & 1 & $1 / 2$ & 2 & $1 / 3$ & 5 & 2 & 3 & 0.15 \\
\hline$I_{2}$ & 2 & 1 & 3 & $1 / 2$ & 6 & 2 & 4 & 0.22 \\
\hline$I_{3}$ & $1 / 2$ & $1 / 3$ & 1 & $1 / 4$ & 3 & 1 & 2 & 0.09 \\
\hline$I_{4}$ & 3 & 2 & 4 & 1 & 8 & 3 & 6 & 0.35 \\
\hline$I_{5}$ & $1 / 5$ & $1 / 6$ & $1 / 3$ & $1 / 8$ & 1 & $1 / 4$ & $1 / 2$ & 0.03 \\
\hline$I_{6}$ & $1 / 2$ & $1 / 2$ & 1 & $1 / 3$ & 4 & 1 & 3 & 0.11 \\
\hline$I_{7}$ & $1 / 3$ & $1 / 4$ & $1 / 2$ & $1 / 6$ & 2 & $1 / 3$ & 1 & 0.05 \\
\hline
\end{tabular}

The condition with $\lambda_{\max }=7.265, C I=0.044, R I=1.32$, and $C R=0.033<0.1$ can satisfy the requirement of consistency check.

\section{Risk Level Determination}

Total efficacy coefficient could be calculated by Eq. (5). Thus the risk grade of water inrush in karst tunnels could be determined with the total efficacy coefficients, as shown in Table 6.

\section{Determining Weight Coefficient}

Subjective weights were derived from the analytic hierarchy process. A judgment matrix (in Table 7) could be obtained by using the 1-9 scale method (in Table 1). The weights of evaluation indices $I_{2-j}$, including waterbearing structure, catchment area of karst water system,

Table 8. Judgment matrix for weights analysis of $I_{4-\mathrm{j}}$.

\begin{tabular}{|c|c|c|c|c|}
\hline $\begin{array}{c}\text { Evaluation } \\
\text { indices }\end{array}$ & $I_{4-1}$ & $I_{4-2}$ & $I_{4-3}$ & $\omega_{4-j}$ \\
\hline$I_{4-1}$ & 1 & 3 & 5 & 0.65 \\
\hline$I_{4-2}$ & $1 / 3$ & 1 & 2 & 0.23 \\
\hline$I_{4-3}$ & $1 / 5$ & $1 / 2$ & 1 & 0.12 \\
\hline
\end{tabular}

The condition with $\lambda_{\max }=3.004, C I=0.002, R I=0.58$, and $C R=0.038<0.1$ can satisfy the requirement of consistency check.

Table 9. Weights of evaluation indices.

\begin{tabular}{|c|c|c|c|c|}
\hline \multicolumn{2}{|c|}{ Evaluation indices } & \multicolumn{2}{|c|}{ Weights } & Order \\
\hline \multicolumn{2}{|c|}{$I_{1}$} & \multicolumn{2}{|c|}{0.15} & 3 \\
\hline \multicolumn{2}{|c|}{$I_{2}$} & \multicolumn{2}{|c|}{0.22} & 2 \\
\hline \multicolumn{2}{|c|}{$I_{3}$} & \multicolumn{2}{|c|}{0.09} & 5 \\
\hline \multirow{3}{*}{$I_{4}$} & $I_{4-1}$ & 0.23 & \multirow{3}{*}{0.35} & \multirow{3}{*}{1} \\
\hline & $I_{4-2}$ & 0.08 & & \\
\hline & $I_{4-3}$ & 0.04 & & \\
\hline \multicolumn{2}{|c|}{$I_{5}$} & \multicolumn{2}{|c|}{0.03} & 7 \\
\hline \multicolumn{2}{|c|}{$I_{6}$} & \multicolumn{2}{|c|}{0.11} & 4 \\
\hline \multicolumn{2}{|c|}{$I_{7}$} & \multicolumn{2}{|c|}{0.05} & 6 \\
\hline
\end{tabular}


and width of fault fracture zone, could be derived from the analytic hierarchy process, and the conducted judgment matrix is presented in Table 8 .

According to the analytic hierarchy process method, the weights of evaluation indices of water inrush were obtained (Table 9). The weights of evaluation indices are different from each other. The weights decrease in the following order: $I_{4}>I_{2}>I_{1}>I_{6}>I_{3}>I_{7}>I_{5}$. For the seven indices, the highest weight for the indices coincides with unfavorable geological conditions, which is equal to 0.35 .

\section{Computational Procedure}

The presented risk model was developed based on Visual Basic. Then single efficacy coefficient, total efficacy coefficient, and weight coefficient were calculated as well as other factors. According to the results, a decision on the grade of the evaluation sample could be provided. The computational procedure and its flow chart are presented in detail in Fig. 2.

\section{Model Test}

The present work uses the efficacy coefficient method to evaluate the risk of water inrush in karst tunnels. To validate the rationality and effectiveness of the preset method, four samples were selected as evaluation objects based on the literature [6] with attributed mathematical theory. Then the four samples were treated with the presented method. As a result, the indices for each sample are listed in Table 10. In the table, total efficacy coefficient and the risk evaluation results of the proposed method in this work are presented in detail.

For sample 1, the total efficacy coefficient is 75.507 , the risk of water inrush belongs to grade III (elevated), and the warning signal is yellow. For samples 2-5, the total efficacy coefficients are all greater than 80 , the risk of water inrush belongs to grade II (high), and the warning signal is orange. According to the value of the total efficacy coefficients, the risk of water inrush for these samples could range from big to small as

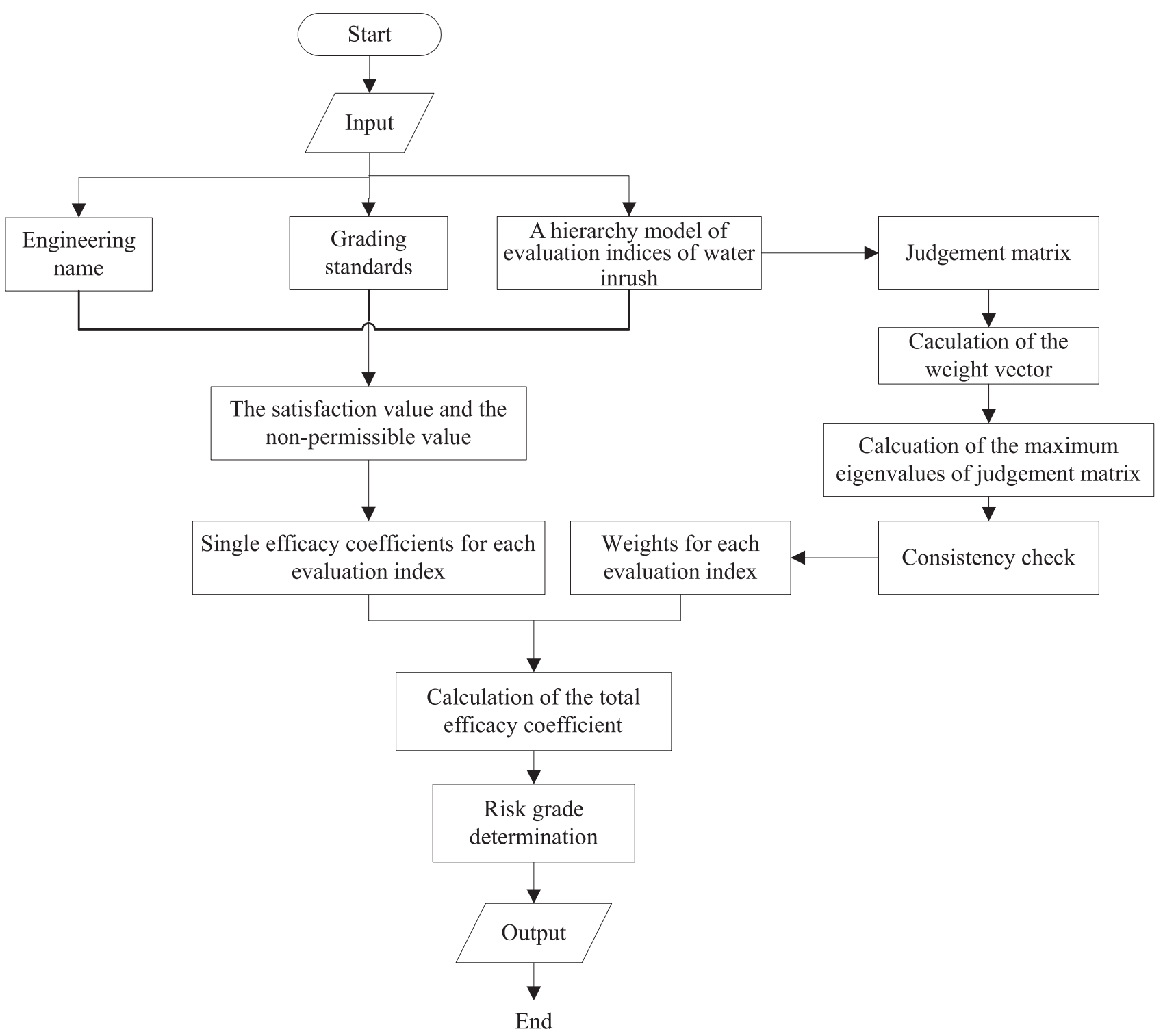

Fig. 2. Flowchart and computational procedure. 
Table 10. Risk grade of water inrush of evaluation samples and comparison.

\begin{tabular}{|c|c|c|c|c|c|c|c|c|c|c|c|}
\hline \multirow{2}{*}{ Sample } & \multirow{2}{*}{ Tunnel kilometrage } & \multicolumn{7}{|c|}{ Evaluation indices } & \multirow{2}{*}{$\begin{array}{c}\text { Total efficacy } \\
\text { coefficient }\end{array}$} & \multirow{2}{*}{$\begin{array}{l}\text { Results } \\
\text { of this } \\
\text { work } \\
\end{array}$} & \multirow{2}{*}{$\begin{array}{c}\text { The field- } \\
\text { observed } \\
\text { results }\end{array}$} \\
\hline & & $I_{1}$ & $I_{2}$ & $I_{3}$ & $I_{4}$ & $I_{5}$ & $I_{6}$ & $I_{7}$ & & & \\
\hline 1 & $\mathrm{~K} 19+240 \sim \mathrm{K} 19+450$ & 90 & 75 & $20 \%$ & 75 & $13^{\circ}$ & 85 & 80 & 75.507 & III & III \\
\hline 2 & $\mathrm{~K} 19+450 \sim \mathrm{K} 19+500$ & 80 & 75 & $40 \%$ & 60 & $16^{\circ}$ & 70 & 65 & 80.447 & II & II \\
\hline 3 & $\mathrm{~K} 19+500 \sim \mathrm{K} 19+760$ & 75 & 75 & $40 \%$ & 60 & $16^{\circ}$ & 70 & 65 & 80.747 & II & II \\
\hline 4 & $\mathrm{~K} 19+760 \sim \mathrm{K} 19+800$ & 60 & 75 & $40 \%$ & 60 & $13^{\circ}$ & 70 & 65 & 81.567 & II & II \\
\hline 5 & $\mathrm{~K} 19+800 \sim \mathrm{K} 20+180$ & 55 & 75 & $30 \%$ & 65 & $13^{\circ}$ & 80 & 70 & 80.027 & II & II \\
\hline
\end{tabular}

Table 11. Risk evaluation result of K19+509 K19+539 in Jigongling Tunnel.

\begin{tabular}{|c|c|c|c|c|c|c|c|c|c|c|c|}
\hline \multirow{3}{*}{$\begin{array}{l}\text { Evaluation } \\
\text { indices }\end{array}$} & \multirow{3}{*}{ Values } & \multirow{3}{*}{$\begin{array}{c}\text { Single } \\
\text { efficacy } \\
\text { coefficient }\end{array}$} & \multirow{3}{*}{$\begin{array}{l}\text { Weights of } \\
\text { each index }\end{array}$} & \multirow{3}{*}{$\begin{array}{c}\text { Total } \\
\text { efficacy } \\
\text { coefficient }\end{array}$} & \multirow{3}{*}{$\begin{array}{l}\text { Results of } \\
\text { this work }\end{array}$} & \multicolumn{5}{|c|}{ Results of attribute mathematical theory } & \multirow{3}{*}{$\begin{array}{c}\text { The field- } \\
\text { observed } \\
\text { results }\end{array}$} \\
\hline & & & & & & \multicolumn{4}{|c|}{ Synthetic attribute measure } & \multirow{2}{*}{$\begin{array}{l}\text { Risk } \\
\text { grade }\end{array}$} & \\
\hline & & & & & & IV & III & II & I & & \\
\hline$I_{1}$ & 0.07 & 71.024 & 0.15 & \multirow{9}{*}{81.828} & \multirow{9}{*}{$\begin{array}{c}\text { II } \\
\text { (Orange) }\end{array}$} & \multirow{9}{*}{0.010} & \multirow{9}{*}{0.347} & \multirow{9}{*}{0.383} & \multirow{9}{*}{0.261} & \multirow{9}{*}{ II } & \multirow{9}{*}{ II } \\
\hline$I_{2}$ & 75 & 100.000 & 0.22 & & & & & & & & \\
\hline$I_{3}$ & $40 \%$ & 86.667 & 0.09 & & & & & & & & \\
\hline$I_{4-1}$ & 62 & 75.200 & 0.23 & & & & & & & & \\
\hline$I_{4-2}$ & 7.5 & 80.000 & 0.08 & & & & & & & & \\
\hline$I_{4-3}$ & 1.0 & 100.000 & 0.04 & & & & & & & & \\
\hline$I_{5}$ & $13^{\circ}$ & 71.556 & 0.03 & & & & & & & & \\
\hline$I_{6}$ & 72 & 71.200 & 0.11 & & & & & & & & \\
\hline$I_{7}$ & 65 & 74.000 & 0.05 & & & & & & & & \\
\hline
\end{tabular}

sample 4, sample 3, sample 2, and sample 5. Furthermore, the present results were compared with the field-observed results, and good agreement could be gained, which could validate the present method to some extent.

\section{Engineering Application}

\section{Engineering Background}

To dig the practical significance, the present method was applied for engineering application. An express highway project was considered. In detail, the project is performed for transshipment over the Three Georges Dam, which is located in the typical karst mountain areas of Hubei Province in China. Meanwhile, Jigongling Tunnel [6] is regarded as the most significant engineering project, which could reflect on the features of the express highway project. Thus Jigongling Tunnel was selected as an investigated object. The tunnel is deep-buried with the length of $4.5 \mathrm{~km}$. The maximum overburden thickness for the tunnel is $338 \mathrm{~m}$. What's more, Jigongling tunnel goes through a complicated geologic environment, which is mainly made up of shale, marl, and dolomitic limestone from $\mathrm{K} 19+240$ to $\mathrm{K} 20+180$. Most important of all, the groundwater is rich in complex geological structure and well-developed karst at the tunnel site. The tunnel goes through the main aquifers, including a weak karst aquifer from $\mathrm{K} 19+450$ to $\mathrm{K} 19+760$, and a strong karst aquifer from $\mathrm{K} 19+760$ to $\mathrm{K} 20+180$.

\section{Risk Evaluation of Water Inrush}

Based on the present efficacy coefficient method, the risk grade of water inrush was investigated from

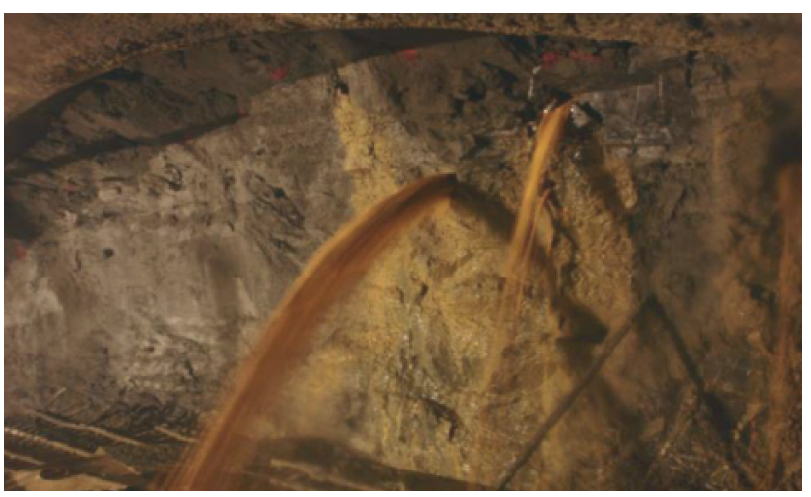

Fig. 3. Jigongling Tunnel face water inrush $($ ZK19+509) (Li et al., 2015). 
K19+509 to K19+539 in Jigongling Tunnel, and the evaluation result is listed in Table 11. For sample 1, the total efficacy coefficient is 81.828 , the risk of water inrush belongs to high grade (II), and the warning signal is orange. According the previous result, the risk grade is also level II using attribute mathematical theory [6]. Thus the result of the present work is in good agreement with the former results. Furthermore, based on the reference of Li et al. (2013), water inrush with a certain pressure occurred during the drilling of boreholes at K19 +509 in Jigongling Tunnel (Fig. 3) and a total water inrush rate is $200 \mathrm{~m}^{3} / \mathrm{h}$ from the boreholes. Therefore, the evaluation result obtained from the efficacy coefficient method is in a good agreement with the practical situation.

\section{Conclusions}

Water inrush is difficult to predict accurately during tunnel construction, especially for karst tunnels. The risk grade of water inrush is essential to ensure the safety of the karst tunnels. In the present work, efficacy coefficient method and analytic hierarchy process method were applied to establish a reasonable analysis model. Meanwhile, the efficacy coefficient method was presented based on the theory of multi-objective programming. The efficacy coefficient method could provide basic evaluation values, which was performed with single efficacy coefficient by considering the main influence factors of water inrush. Then the multiple factors were selected as evaluation indices for single efficacy coefficients. Moreover, weight coefficient was determined by AHP for each evaluation index, since the weight coefficients could not only provide useful information for the confirmation of risk grade of water inrush but also avoid the individual influence on subjective methods. Based on the weight coefficients and the single efficacy coefficients, the total efficacy coefficient was presented to specify the risk grade of the evaluation samples. Furthermore, the evaluation result for Jigongling Tunnel was compared with the construction situation and the relative analysis results of attribute mathematical theory. It is shown that the presented risk analysis method is valid to predict the risk grade of water inrush in karst tunnels. In addition, the presented method on risk analysis could provide credible evaluation results for both risk design and risk management of projects in karst areas. Moreover, the presented method is feasible and effective, which could make up for the shortcoming of traditional evaluation methods.

\section{Acknowledgements}

Financial support from the Fundamental Research Funds for the Central Universities (2017XKQY074) is sincerely acknowledged.

\section{References}

1. AN Z., DI Q., WU F., WANG G., WANG R. Geophysical exploration for a long deep tunnel to divert water from the Yangtze to the Yellow River [J]. China. B Eng Geol Environ, 711, 2012.

2. HUANG R., HUANG J., JU N., LI Y. Automated tunnel rock classification using rock engineering systems [J]. Eng Geol, 156, 2013.

3. ZHANG C., FENG X.T., ZHOU H. Estimation of in situ stress along deep tunnels buried in complex geological conditions [J]. Int J Rock Mech Min, 52, 2012.

4. LI L., LEI T., LI S., ZHANG Q., XU Z., SHI S., ZHOU Z. Risk assessment of water inrush in karst $t$ unnels and software development [J]. Arab J Geosci, 8, 2014.

5. LIN C.N., LI L.P., HAN X.R. Research on forecast method of tunnel water inrush in complex karst areas $[\mathrm{J}]$. Chin $\mathrm{J}$ Rock Soil Mech, 27, 2008.

6. LI S.C., ZHOU Z.Q., LI L.P., XU Z.H., ZHANG Q.Q., SHI S.S. Risk assessment of water inrush in karst tunnels based on attribute synthetic evaluation system [J]. Tunn Undergr Space Technol, 38, 2013.

7. HWANG J.H., LU C.C. A semi-analytical method for analyzing the tunnel water inflow $[\mathrm{J}]$. Tunn Undergr Space Technol, 22, 2007.

8. LU Y.L., WANG L.G. Numerical simulation of mininginduced fracture evolution and water flow in coal seam floor above a confined aquifer [J]. Comput Geotech, 67, 2015.

9. YAO B.H., BAI H.B., ZHANG B.Y. Numerical simulation on the risk of roof water inrush in Wuyang Coal Mine [J]. Int J Min Sci Technol, 22, 2012.

10. WANG Y., YANG W.F., LI M., LIU X. Risk assessment of floor water inrush incoal mines based on secondary fuzzy comprehensive evaluation [J]. Int J Rock Mech Min, 52, 2012.

11. CHEN J.M., YANG R.S. Analysis of mine water inrush accident based on FTA [J]. Procedia Environmental Sciences, 11, 2011.

12. OLGA Š., JIR ־́.Š., DANIEL S. Probabilistic assessment of tunnel construction performance based on data [J]. Tunn Undergr Space Technol, 37, 2013a.

13. OLGA Š., EVA N., MICHAL Š, JIR Í.Š. Probabilistic models for tunnel construction risk assessment [J]. Adv Eng Softw, 62-63, 2013b.

14. FOULADGAR M.M., YAZDANI-CHAMZINI A., ZAVADSKAS E.K. Risk evaluation of tunneling projects [J]. Arch Civ Mech Eng, 12, 2012.

15. HODLUR G., PRAKASH R.M, DESHMUKH, S. SINGH $\mathrm{V}$. Role of some salient geo-physical, geochemical, and hydrogeological parameters in the exploration of fresh groundwater in a brackish terrain [J]. Environ Geol, 41, 2002.

16. BUKOWSKI P. Water hazard assessment in active shafts in Upper Silesian Coal Basin mines [J]. Mine Water Environ, 30, 2011.

17. LI Z.L., WANG X.H., XIE L.Z. Risk evaluation and comprehensive geological prediction based on fuzzy wavelet neural network during tunneling in karst area $[\mathrm{J}]$. Electron $\mathrm{J}$ Geotech Eng, 17, 2012.

18. SHI L.Q., QIU M., WEI W.X., XU D.J., HAN J. Water inrush evaluation of coal seam floor by integrating the water 
inrush coefficient and the information of water abundance [J]. Int J Rock Mech Min, 24, 2014.

19. MENG Z.P., LI G.Q., XIE X.T. A geological assessment method of floor water inrush risk and its application [J]. Eng Geol, 143-144, 2012.

20. LI X.P., LI Y.N. Research on risk assessment system for water inrush in the karst tunnel construction based on GIS: Case study on the diversion tunnel groups of the Jinping II Hydropower Station [J]. Tunn Undergr Space Technol, 40, 2014.

21. MATTHIAS S., NIELS P.H., ARILD R., HARALD B. Risk assessment of road tunnels using Bayesian networks [J]. Procedia - Social and Behavioral Sciences, 48, 2012.

22. WANG Y.C., YIN X., JING H.W., LIU R.C., SU H.J. A novel model of the cloud for risk analysis of water inrush in karst tunnels. ENVIRON EARTH SCI, 75, 2016.

23. WANG Y.C., JING H.W., YU L.Y., SU H.J., LUO N. Set pair analysis for risk assessment of water inrush in karst tunnels[J]. B ENG GEOL ENVIRON, 7, 2016.

24. WANG Y.C., JING H.W., HAN L.J., YU L.Y., ZHANG Q. Risk analysis on swell -shrink capacity of expansive soils with efficacy coefficient method and entropy coefficient method[J]. APPL CLAY SCI, 99, 2014.
25. WANG Y.C., JING H.W., ZHANG Q., LUO N., YIN X. Prediction of Collapse Scope of Deep-Buried Tunnels Using Pressure Arch Theory[J]. Math Probl Eng, 3-4, 2016.

26. WANG Y.C., JING H.W., SU H.J., XIE J.Y. Effect of a Fault Fracture Zone on the Stability of Tunnel-Surrounding Rock[J]. INT J GEOMECH, 04016135, 2016.

27. WANG Y.C., ZHAO N., JING H.W., Meng B., Yin X. A novel model of the ideal point method coupled with objective and subjective weighting method for evaluation of surrounding rock stability[J]. Math Probl Eng, 12, 2016.

28. XU J., ZHANG Q., WU J. Application of efficient method to determination of rock preferred structural plane $[\mathrm{J}]$. Chin $\mathrm{J}$ Geotech Eng, 30, 2008.

29. WANG Y.C., SHANG Y.Q., SUN H.Y. Study of prediction of rockburst intensity based on efficacy coefficient method [J]. Chin J Rock Soil Mech, 31, 2010.

30. SAATY T.L. Decision Making for Leaders: The Analytic Hierarchy Process for Decisions in a Complex World $[\mathrm{M}]$. Pittsburgh, Pennsylvania: RWS Publications. ISBN 0-9620317-8-X, 2008.

31. ZHOU Z.Q., LI S.C., LI L.P., SHI S.S., SONG S.G., WANG K. Attribute recognition model and its application of fatalness assessment of water inrush in karst tunnels [J]. Rock Soil Mech, 34, 2013. 